\title{
Antigen-specific multifunctional T-cells in sarcoidosis patients with Löfgren's syndrome
}

\begin{abstract}
Maria Wikén*, Mahyar Ostadkarampour*, Anders Eklund*, Matthew Willett”, Edward Chen" ${ }^{\#}$ David Moller", Johan Grunewald* and Jan Wahlström*
\end{abstract}

ABSTRACT: Sarcoidosis is a granulomatous disease of unknown aetiology, mainly affecting the lungs. Recently, T-cell responses towards a specific mycobacterial protein, catalase-peroxidase (mKatG), were observed in sarcoidosis patients.

Bronchoalveolar lavage (BAL) fluid and peripheral blood were obtained from a total of 23 sarcoidosis patients, of whom 13 had Löfgren's syndrome and lung accumulations of T-cell receptor AV2S3+ T-cells. Using six-colour flow cytometry in combination with intracellular cytokine staining, T-cell subsets were studied with regard to interferon (IFN)- $\gamma$, tumour necrosis factor (TNF) and interleukin-2 production, after stimulation with mKatG or Mycobacterium tuberculosis purified protein derivate (PPD).

Stimulation with $\mathrm{mKatG}$ resulted in higher simultaneous IFN- $\gamma$ and TNF production, but less single IFN- $\gamma$ production, from total BAL fluid CD4+ T-cells of Löfgren's syndrome patients, when compared with non-Löfgren's patients. In contrast, PPD stimulation gave rise to largely similar cytokine responses in both patient subgroups. Furthermore, mKatG stimulated higher IFN- $\gamma$ production in BAL fluid and blood AV2S3+ T-cells than AV2S3- T-cells, whereas the opposite was seen in BAL fluid with PPD stimulation.

Our finding that patients with Löfgren's syndrome exhibited a more pronounced multifunctional cytokine profile (simultaneous IFN- $\gamma$ and TNF production) towards the mycobacterial protein mKatG may help to explain the distinct disease presentation in this patient subgroup.

KEYWORDS: Löfgren's syndrome, multifunctional T-cells, Mycobacterium tuberculosis, sarcoidosis, T-cells

arcoidosis is a multisystem granulomatous disorder, commonly affecting the lungs. Active disease is characterised by increased numbers of lymphocytes, in particular activated CD4+ T-cells, in the lower airways. Increased mRNA and protein levels of interleukin (IL)-2 and interferon (IFN)- $\gamma$ in the lung support sarcoidosis being a T-helper cell (Th) type 1-mediated disease [1-3]. IL-2 promotes the Th1 immune response and contributes to T-cell proliferation, whereas IFN- $\gamma$, together with the Tcell- and macrophage-derived cytokine tumour necrosis factor (TNF), play important roles in orchestrating maintenance of the characteristic granuloma formation $[4,5]$.

T-cells owe their capacity to recognise virtually any pathogen to their enormously variable T-cell receptor (TCR) for antigen. Collectively, the Tcells in the body encompass millions of different TCR specificities, but each T-cell only expresses TCRs with a single specificity. T-cells recognise antigens in the form of peptides presented by human leukocyte antigen (HLA) molecules on antigen-presenting cells, such as dendritic cells and macrophages.

We previously demonstrated that Swedish sarcoidosis patients of HLA type DRB1*0301 (DR3) virtually always have large accumulations, socalled T-cell expansions, in their lungs of CD4+ (Th) cells with a particular TCR that uses the AV2S3 gene segment [6]. This suggests that a specific antigen presented by HLA-DR3 molecules has caused the activation and proliferation of the TCR AV2S3+ cells. The lung AV2S3+ CD4+ T-cells

\section{AFFILIATIONS}

*Respiratory Medicine Unit, Dept of Medicine Solna, Karolinska Institutet, Stockholm, Sweden.

\#Division of Pulmonary and Critical Care Medicine, Dept of Medicine, The Johns Hopkins University School of Medicine, Baltimore, MD, USA.

CORRESPONDENCE

M. Wikén

Karolinska Institutet

Dept of Medicine

Lung Research Laboratory

L4: 01

Karolinska University Hospital

Solna

17176 Stockholm

Sweden

E-mail: Maria.Wiken@ki.se

Received:

Oct 252010

Accepted after revision:

Nov 232011

First published online:

Dec 192011 
were found to be significantly more differentiated and activated when compared with lung CD4+ T-cells expressing other TCR variable gene segments $[7,8]$, they were also associated with active disease [9]. We have also shown that Swedish DR3+ patients often present with an acute disease onset and commonly have Löfgren's syndrome, and normally recover spontaneously within 2 yrs.

The aetiology of sarcoidosis is still unknown. However, involvement of mycobacterial species has been proposed, since mycobacterial DNA has been found in sarcoidosis tissues and lymph nodes [10]. Recently, SoNG et al. [11] identified a specific protein, mycobacterial catalase-peroxidase (mKatG), in sarcoidosis tissue but not in healthy subjects. T-cell responses against $\mathrm{mKatG}$ have been observed in sarcoidosis lung [12, 13] and peripheral blood mononuclear cells [14], but the specificity of Tcells responding to $\mathrm{mKatG}$ has not been characterised in detail. Although we have data to support that AV2S3+ T-cells can recognise mycobacterial antigens [15], we have not been able to firmly establish the specificity of the AV2S3+ lung T-cells.

We have previously shown that T-cells of the majority of Swedish sarcoidosis patients and healthy purified protein derivative (PPD)+ individuals (i.e. subjects with proven antimycobacterial T-cell responses), but not PPD- individuals, respond to $\mathrm{mKatG}$ with IFN- $\gamma$ production in an ELISPOT assay [12]. The aim of this study was to elucidate the ability of total lung and blood CD4+ or CD8+ T-cells and CD4+ TCR AV2S3+ Tcells of patients with or without Löfgren's syndrome to respond to the specific mycobacterial antigen $\mathrm{mKatG}$ and to PPD, by measuring the production of IFN- $\gamma$, TNF and IL-2 by flow cytometry. We also investigated whether these T-cells displayed a single-function or multifunctional cytokine profiles in response to antigen stimulation, since T-cells of the latter kind have been shown to be particularly potent effector cells.

\section{MATERIALS AND METHODS}

\section{Study subjects}

The sarcoidosis patients included in this study were referred to the Respiratory Medicine Unit (Karolinska University Hospital, Stockholm, Sweden) for primary diagnostic investigation (except for four already-established sarcoidosis patients, who were recruited from their routine check-ups at the outpatient clinic). In all patients, the diagnosis was based on chest radiographic findings, pulmonary function tests (vital capacity, forced vital capacity and diffusing capacity of the lung for carbon monoxide), results of bronchoscopy and bronchoalveolar lavage (BAL), and clinical symptoms compatible with sarcoidosis, according to the criteria established by the World Association of Sarcoidosis and other Granulomatous Disorders [16]. Written informed consent was obtained from all subjects and the Regional Ethical Review Board (Stockholm, Sweden) approved the study.

A total of 23 sarcoidosis patients participated in the study (clinical and BAL fluid characteristics are given in table 1). 13 patients with an acute disease onset (median age 37 yrs, range 29-56 yrs; nine males and four females) were characterised as having recently diagnosed Löfgren's syndrome (i.e. erythema nodosum and/or ankle arthritis, fever and bilateral hilar lymphadenopathy with or without lung parenchymal infiltration [17]). They all had an increased frequency (a so-called

\begin{tabular}{|c|c|c|}
\hline & $\begin{array}{l}\text { Löfgren's } \\
\text { syndrome }\end{array}$ & Non-Löfgren's \\
\hline Patients n & 13 & 10 \\
\hline Males/females n & 9/4 & $8 / 2$ \\
\hline Age yrs median (range) & $37(29-56)$ & $48(33-67)^{\star}$ \\
\hline $\begin{array}{l}\text { Current smokers/ex-smokers/ } \\
\text { never-smokers n }\end{array}$ & 3/2/8 & $1 / 4 / 5$ \\
\hline $\begin{array}{l}\text { Radiographic stage } 0 / / 1 / 1 / / I I / I V ~ n \\
\text { BAL analyses }\end{array}$ & 0/10/3/0/0 & $0 / 2 / 3 / 2 / 3$ \\
\hline Recovery \% of instilled volume & $67(60-72)$ & $59(55-68)$ \\
\hline Viability \% & 94 (93-96) & 95 (93-98) \\
\hline Total cell concentration $\times 10^{6}$ cells $\cdot \mathrm{L}^{-1}$ & $172(99-248)$ & $160(125-191)$ \\
\hline Total cell number $\times 10^{6}$ cells & $26(13-38)$ & $23(16-32)$ \\
\hline \multicolumn{3}{|l|}{ Differential cell counts } \\
\hline Macrophages \% & $77(68-85)$ & $76(64-86)$ \\
\hline Macrophages $\times 10^{6}$ cells $\cdot \mathrm{L}^{-1}$ & $128(81-174)$ & $124(90-154)$ \\
\hline Lymphocytes \% & $23(13-30)$ & $22(13-34)$ \\
\hline Lymphocytes $\times 10^{6}$ cells $\cdot L^{-1}$ & $33(13-66)$ & $27(14-67)$ \\
\hline Neutrophils \% & $1.0(0.4-1.7)$ & $1.6(0.4-2.3)$ \\
\hline Neutrophils $\times 10^{6}$ cells $\cdot L^{-1}$ & $1.3(0.9-2.9)$ & $2.5(0.4-3.3)$ \\
\hline Eosinophils \% & $0.2(0-0.4)$ & $0.4(0.2-0.8)$ \\
\hline Eosinophils $\times 10^{6}$ cells $\cdot L^{-1}$ & $0.3(0-0.5)$ & $0.6(0.2-1.3)$ \\
\hline CD4+/CD8+ T-cell ratio & $5.0(2.5-11)$ & $4.5(3.5-9.0)$ \\
\hline AV2S3+ T-cells \% of CD4+ T-cells & $28(22-37)$ & $3.5(2.5-6.7)^{\star \star \star}$ \\
\hline $\begin{array}{l}\text { Blood AV2S3+ T-cells \% of CD4+ } \\
\text { T-cells }\end{array}$ & $4.4(3.9-5.2)$ & ND \\
\hline \multicolumn{3}{|l|}{ Pulmonary function tests } \\
\hline VC \% pred & $96(86-104)$ & 90 (78-99) \\
\hline FEV $1 \%$ pred & $93(76-102)$ & $90(75-101)$ \\
\hline$D\llcorner, \mathrm{CO} \%$ pred & $94(91-107)^{\#}$ & $82(24-83)^{\bullet}$ \\
\hline
\end{tabular}

Data are presented as median (interquartile range), unless otherwise stated. BAL: bronchoalveolar lavage; VC: vital capacity; \% pred: \% predicted; FEV1: forced expiratory volume in $1 \mathrm{~s} ; \mathrm{DL}, \mathrm{CO}$ : diffusing capacity of the lung for carbon monoxide; ND: not determined. ${ }^{*}: \mathrm{n}=12 ;{ }^{\bullet}: \mathrm{n}=3{ }^{*}{ }^{*}: \mathrm{p}<0.05$ by Mann-Whitney U-test; ${ }^{* *}: p<0.001$ by Mann-Whitney U-test.

T-cell expansion) of TCR AV2S3+ CD4+ T-cells in their BAL fluid. The increase ( $>10.5 \%$ of all CD4+ T-cells) was defined as three times the median AV2S3+ percentage of CD4+ T-cells in peripheral blood of healthy subjects (i.e. $3 \times 3.5 \%$ ) [18]. 11 of the patients with Löfgren's syndrome had haplotype HLA-DR3 and two had haplotype HLA-DRB3*0101 (the corresponding HLA molecules are structurally similar and Scandinavian patients with either haplotype show an increase $>10.5 \%$ AV2S3+ cells $[19,20]) .10$ patients did not have Löfgren's syndrome, whereof four patients had been followed for 320 yrs (median age 48 yrs, range 33-67 yrs; eight males and two females). All had $<10.5 \%$ AV2S3+ T-cells in their BAL fluid and all were HLA-DR3-. Thus, from a phenotypic and immunogenetic point of view, the patient groups were rather homogenous, since for all practical purposes, all Löfgren's syndrome patients were DR3+ and all non-Löfgren's patients were DR3-. Out of the four patients with chronic disease, three were treated with oral corticosteroids and one with methotrexate to control disease activity. No Löfgren's syndrome 

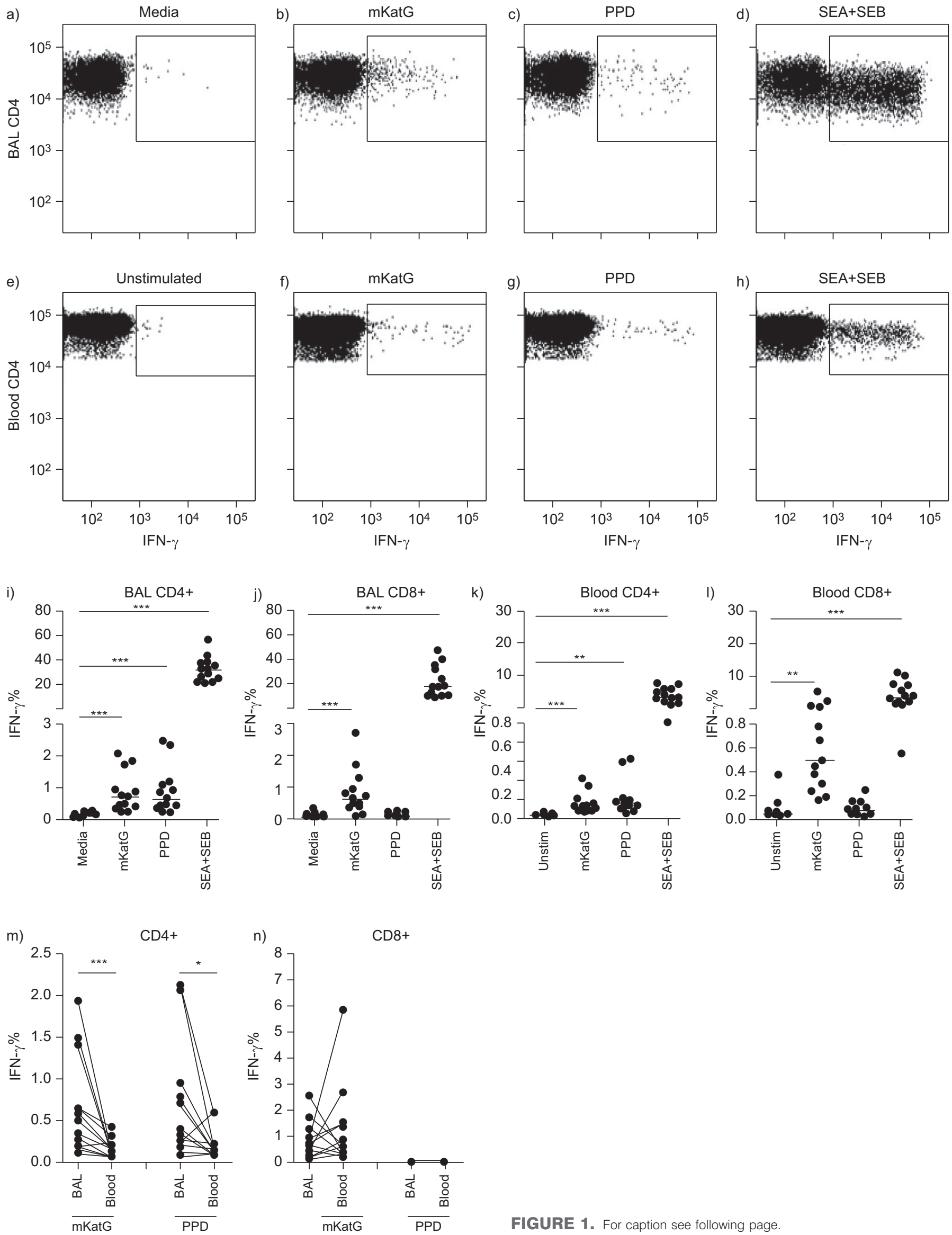

FIGURE 1. For caption see following page. 
FIGURE 1. T-cells in bronchoalveolar lavage (BAL) fluid and whole blood of patients with Löfgren's syndrome respond with interferon (IFN)- $\gamma$ production towards mycobacterial proteins. Representative flow cytometry plots of IFN- $\gamma$ production in a-d) BAL fluid or e-h) whole blood CD4+ T-cells, in response to b, f) mycobacterial catalase-peroxidase ( $\mathrm{mKatG}$ ) or $\mathrm{c}, \mathrm{g}$ ) purified protein derivative (PPD). a) Media alone or e) unstimulated (unstim) whole blood were used as negative controls. The superantigens d, h) Staphylococcus enterotoxin A (SEA) and Staphylococcus enterotoxin B (SEB) were used as a positive control. Percentages of IFN- $\gamma$-expressing i, j) BAL fluid and $\mathrm{k}, \mathrm{l}$ ) whole blood i, k) CD4+ or j, l) CD8+ T-cells, in response to mKatG or PPD. Statistical analyses in were performed using raw data, i.e. background (cytokine production in BAL after incubation in media alone, or in unstimulated whole blood) was not deducted. Comparison between BAL and blood in the percentages of IFN- $\gamma$ expressing m) CD4+ or n) CD8+ T-cells after stimulation with mKatG or PPD. Statistical analyses were performed after deduction of background. - : median percentage of cytokine-expressing cells. *: $p<0.05$ by Wilcoxon signed-rank test; **: $p<0.01$ by Wilcoxon signed-rank test; $* \star *: p<0.001$ by Wilcoxon signed-rank test.

patient received oral corticosteroids. No patient in either subgroup showed any signs of a lower respiratory tract infection at least 4 weeks prior to the bronchoscopy, but one Löfgren's syndrome patient had an upper respiratory tract infection 1 week before BAL.

\section{$B A L$ procedure and handling of BAL fluid and whole blood cells}

BAL was performed as previously described [21]. Sample handling is described in the online supplementary material.

\section{Intracellular cytokine staining and flow cytometry}

Full details can be found in the online supplementary material. BAL cells and whole blood were stimulated with recombinant mKatG, PPD (from Mycobacterium tuberculosis) or a combination of Staphylococcus enterotoxins A and B as a positive control. Unstimulated BAL cells in medium alone and unstimulated whole blood were used as negative controls.

\section{Statistical analysis}

In order to determine whether there were any significant above-background responses to the antigens, raw data (without background deduction) was used in the comparisons with medium alone or unstimulated whole blood. In all other analyses, background cytokine expression was deducted to focus on the antigen-triggered cytokine production. The Wilcoxon signed-rank test was used for comparisons between BAL and whole blood, or comparisons between various cell types in the same individual. Comparisons between different subgroups of sarcoidosis patients were performed using the Mann-Whitney U-test. All statistical analyses were performed with GraphPad PRISM 4.03 (GraphPad Software Inc., San Diego, CA, USA). p-values $<0.05$ were regarded as significant.

\section{RESULTS}

\section{Cytokine responses to $\mathrm{mKatG}$ in BAL and whole blood T-cells of patients with and without Löfgren's syndrome}

Both in the BAL fluid and whole blood of 13 patients with Löfgren's syndrome, CD4+ T-cells responded with IFN- $\gamma$ production after $\mathrm{mKatG}$ and after PPD stimulation, whereas BAL and whole blood CD8+ T-cells responded with IFN- $\gamma$ production only after $\mathrm{mKatG}$ stimulation (fig. $1 \mathrm{a}-1$ and table S1). The patterns of TNF production in BAL and whole blood were broadly similar to those for IFN- $\gamma$, while antigenspecific cells producing IL-2 were confined to the CD4+ subset and mainly directed to PPD (fig. S1).

Comparing BAL and whole blood T-cell responses, we found that BAL CD4+ T-cells responded with IFN- $\gamma$ and TNF production to a significantly higher extent than whole blood CD4+ T-cells after mKatG stimulation, as well as after PPD stimulation. The cytokine response in CD8+ T-cells, which was dominated by IFN- $\gamma$, did not differ between BAL and whole blood after $\mathrm{mKatG}$ or PPD stimulation (fig. $1 \mathrm{~m}$ and $\mathrm{n}$, and data not shown).

We also performed the same analysis in 10 patients without Löfgren's syndrome. Overall, patients with Löfgren's syndrome and non-Löfgren's patients exhibited similar cytokine responses towards in vitro antigen stimulation (for nonLöfgren's data, see fig. S2). However, some differences were noted; for example, stimulation with PPD resulted in more BAL CD4+ cells expressing TNF among patients with Löfgren's syndrome, while mKatG stimulated BAL CD4+ cells to a similar frequency of IFN- $\gamma$ and TNF production in both patient subgroups (fig. S2d). We could not observe any differences between the four treated patients with chronic disease and other non-Löfgren's patients regarding any of the analyses in the results section. Likewise, the smokers and the patient with prior upper respiratory infection did not stand out in any particular way.

\section{Cytokine responses to MKatG in TCR AV2S3+ CD4+ T-cells}

All Löfgren's syndrome patients participating in our study had a lung accumulation (so-called expansion) of TCR AV2S3+ CD4+ T-cells (median $28 \%$ of CD4+ T-cells), and median whole blood TCR AV2S3+ CD4+ T-cells was $4.4 \%$. We analysed the percentage of cytokine-producing CD4+ AV2S3+ or AV2S3- Tcells that responded to stimuli. mKatG (compared with medium alone) stimulated both BAL AV2S3+ and AV2S3- Tcells to produce IFN- $\gamma$ (fig. 2i). However, comparing these two subsets, there was a significantly higher frequency of mKatGreactive IFN- $\gamma$-producing cells within the AV2S3+ subset (fig. $2 \mathrm{j}$ and table S1). The AV2S3+ and AV2S3- cells also responded with TNF production, to the same extent, whereas the production of IL-2 was very low in both subsets (data not shown). In contrast, after stimulation of BAL cells with PPD, the IFN- $\gamma$, TNF and IL-2 responses were dominant in AV2S3cells (fig. $2 \mathrm{k}$ and data not shown). That AV2S3+ cells are preferentially stimulated by $\mathrm{mKatG}$ is also supported by the finding that the fraction of antigen-triggered IFN- $\gamma$-producing CD4+ cells that are AV2S3+ is almost doubled after mKatG compared with PPD stimulation $(\mathrm{p}<0.001)$ (fig. S3d) and a significant difference $(p<0.01)$ is found also for TNF.

In addition, in whole blood, $\mathrm{mKatG}$ stimulated the AV2S3+ Tcells to produce significantly more IFN- $\gamma$ and TNF than the AV2S3- T-cells, whereas IL-2 production did not differ between the subsets (fig. 21 and data not shown).

Spontaneous cytokine production was also assessed and compared between AV2S3+ and AV2S3- cells (detailed results can be found in the online supplementary material). In BAL and whole blood, the AV2S3+ cells expressed more TNF and IL-2. 

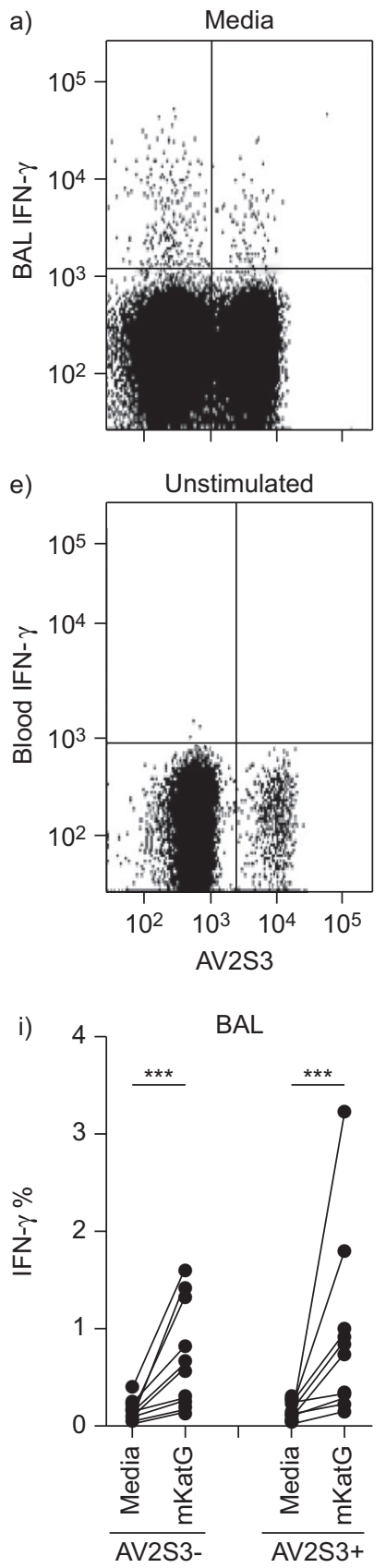

f)
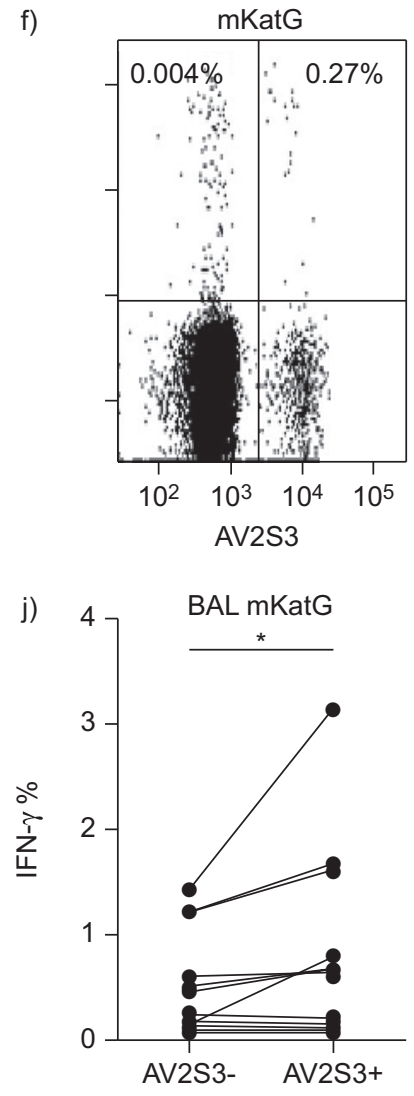

g)
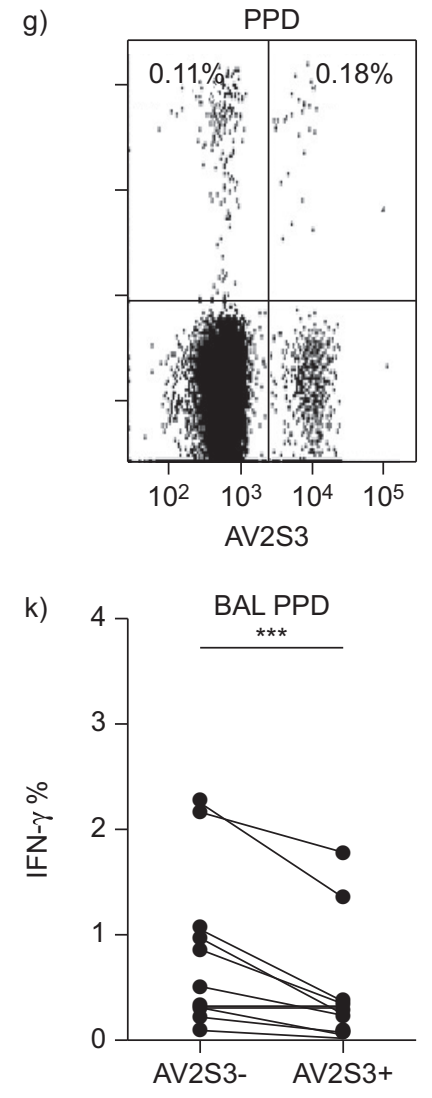

d)

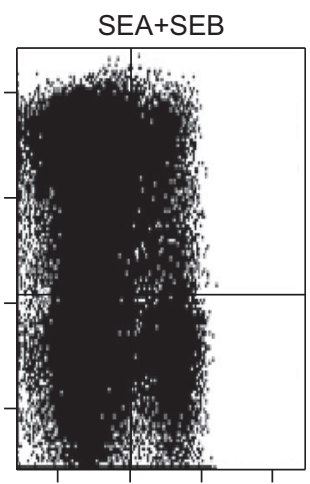

h)

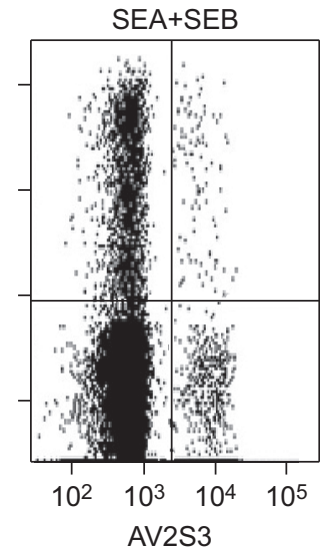

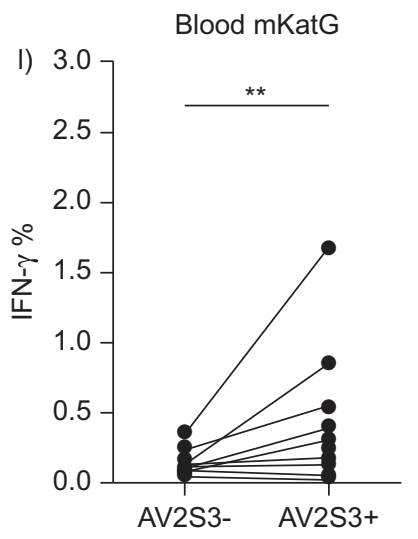

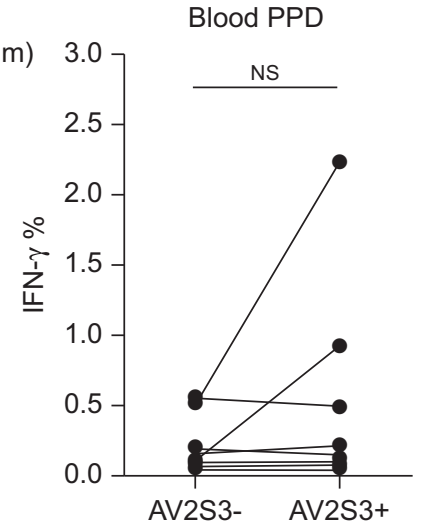

FIGURE 2. For caption see next page. 
FIGURE 2. Greater bronchoalveolar lavage (BAL) and whole blood reactivity towards mycobacterial catalase-peroxidase (mKatG) in T-cell receptor (TCR) AV2S3+ compared with AV2S3- CD4+ T-cells of patients with Löfgren's syndrome. Representative flow cytometry plots of interferon (IFN)- $\gamma$ production in a-d) BAL and e-h) blood TCR AV2S3+ or AV2S3- T-cells, in response to b, f) MKatG or c, g) purified protein derivative (PPD). a) Media alone or e) unstimulated whole blood were used as negative controls. The superantigens d, h) Staphylococcus enterotoxin A (SEA) and Staphylococcus enterotoxin B (SEB) were used as positive controls. i) Comparisons of the percentages of IFN- $\gamma$-expressing BAL TCR AV2S3- and AV2S3+ CD4+ T-cells in media alone and after stimulation with mKatG. Statistical analyses were performed using raw data, i.e. background (cytokine production in BAL after incubation in media alone) was not deducted. Percentages of IFN- $\gamma$-expressing j, k) BAL and I, m) blood TCR AV2S3and AV2S3+ CD4+ T-cells, in response to j, I) mKatG or k, m) PPD. Statistical analyses were performed after deduction of background. -: median percentage of cytokineexpressing cells. NS: nonsignificant. *: $p<0.05$ by Wilcoxon signed-rank test; **: $p<0.01$ by Wilcoxon signed-rank test; $* \star *$ : $p<0.001$ by Wilcoxon signed-rank test.

Comparisons between BAL and whole blood regarding the fractions of AV2S3+ and AV2S3- cells that responded to antigenic stimulation are given in the online supplement.

\section{Higher proportion of multifunctional T-cells reactive to mKatG in patients with Löfgren's syndrome}

The most striking difference between patients with and without Löfgren's syndrome was discovered when comparing the proportions of single-function and multifunctional cytokine-producing cells following $\mathrm{mKatG}$ stimulation. Multifunctional T-cells, i.e. T-cells that simultaneously produce two or more cytokines, are particularly potent effector cells. We analysed the fractions of total $\mathrm{mKatG}$ - or PPD-reactive BAL CD4+ T-cells that displayed any of the following cytokine patterns: IFN- $\gamma$ production alone; TNF production alone; or simultaneous IFN- $\gamma$ and TNF production. In other words, the total number of cells that responded to antigen with any of these three patterns was set to $100 \%$. We found that mKatG stimulated BAL CD4+ T-cells of Löfgren's syndrome patients to significantly less production of IFN- $\gamma$ alone compared with non-Löfgren's patients (fig. $3 c-e$ ). In sharp contrast, Löfgren's syndrome patients had a higher $\mathrm{mKatG}$-induced simultaneous IFN- $\gamma$ and TNF production, as well as higher production of TNF alone. However, PPD stimulation gave rise to similar cytokine profiles in both patient subgroups (fig. $3 \mathrm{f}-\mathrm{h}$ ).

The cytokine patterns in the BAL AV2S3+ and AV2S3- T-cells mirrored that of total CD4+ T-cells (data not shown). Thus, the aforementioned more multifunctional profile of $\mathrm{mKatG}$-reactive cells in Löfgren's syndrome patients was a property of CD4+ cells in general and not particular to TCR AV2S3. The numbers of antigen-reactive BAL CD8+ T-cells was too low to reliably subdivide them further into single-function and multifunctional subsets, but generally, there was a marked dominance of single IFN- $\gamma$ production (data not shown).

\section{Mycobacterial mKatG and PPD trigger T-cells with different cytokine profiles}

A comparison between the two antigenic stimuli showed that $\mathrm{mKatG}$ and PPD stimulation resulted in different cytokine profiles of BAL CD4+ T-cells. mKatG stimulated significantly more single IFN- $\gamma$ production, and significantly less simultaneous IFN- $\gamma$ and TNF production compared with PPD, as fractions of all antigen-responsive cells (fig. 4). These differences between mKatG and PPD responses were also statistically significant when analysed in each patient group separately, and most pronounced in the non-Löfgren's patients (data not shown). The production of TNF alone was similar after $\mathrm{mKatG}$ or PPD stimulation.

\section{Higher cytokine content in multifunctional T-cells}

The median fluorescent intensity (MFI) of antibody-labelled cytokines is directly related to the cytokine content on a percell basis [22]. In our study, the highest MFI values were seen for BAL CD4+ T-cells producing two cytokines simultaneously, as compared with BAL CD4+ T-cells producing only one of the measured cytokines, both after mKatG or PPD stimulation (fig. 5). The MFI analyses were only performed in patients with Löfgren's syndrome. A statistical comparison of MFI values showed that the multifunctional T-cells produced approximately three-fold more IFN- $\gamma$ and three-fold more TNF after mKatG stimulation, and approximately eight-fold more IFN- $\gamma$ and seven-fold more TNF after PPD stimulation, when compared with cells producing either of the cytokines alone. These differences in relative cytokine content increases were statistically significant $(\mathrm{p}=0.0002$ for both IFN- $\gamma$ and TNF), i.e. PPD induces multifunctional cells with relatively higher per-cell cytokine content than mKatG. In blood, the MFI profiles mirrored those in BAL (fig. S4).

\section{Cytokine response in CD27+ or CD27- T-cells of sarcoidosis patients}

CD27 is a co-stimulatory T-cell surface marker expressed on naïve T-cells and lost after prolonged activation. In BAL, the majority of CD4+ T-cells were CD27-, whereas the dominating subset in whole blood was CD27+ T-cells. The result from an analysis of 13 patients (of which five had Löfgren's syndrome) showed that BAL CD4+ CD27- T-cells produced more IFN- $\gamma$ in response to $\mathrm{mKatG}$ or PPD as compared with CD4+ CD27+ Tcells (fig. 6). In contrast, the CD4+ CD27+ T-cells produced more IFN- $\gamma$ in whole blood. There were no differences between patient subgroups. BAL CD8+ T-cells, either expressing or lacking CD27 expression, responded to mKatG to the same extent (data not shown).

\section{DISCUSSION}

In the present study, we investigated the T-cell responses in BAL and whole blood of patients with and without Löfgren's syndrome, after in vitro stimulation with mycobacterial proteins. Interestingly, we found that the BAL CD4+ T-cells of Löfgren's syndrome patients responded to mKatG with a significantly more pronounced multifunctional cytokine profile, as well as TNF alone, than non-Löfgren's patients, who exhibited a more distinct single-functional cytokine profile, with production of IFN- $\gamma$ alone. Furthermore, we showed for the first time that a specific mycobacterial antigen, $\mathrm{mKatG}$, triggers both BAL and blood CD4+ TCR AV2S3+ T-cells to cytokine production. In addition, lung and blood CD4+ and CD8+ T-cells responded to $\mathrm{mKatG}$ stimulation. 
a)

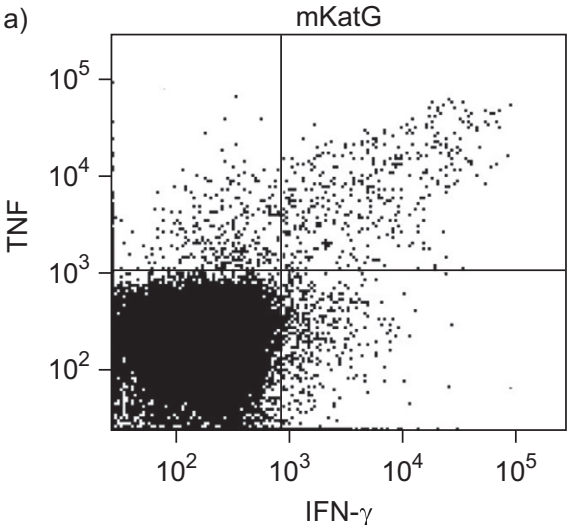

c) BAL CD4+-mKatG

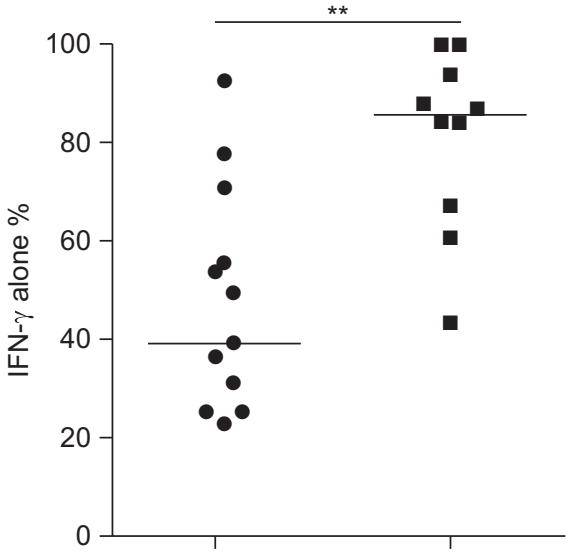

f)

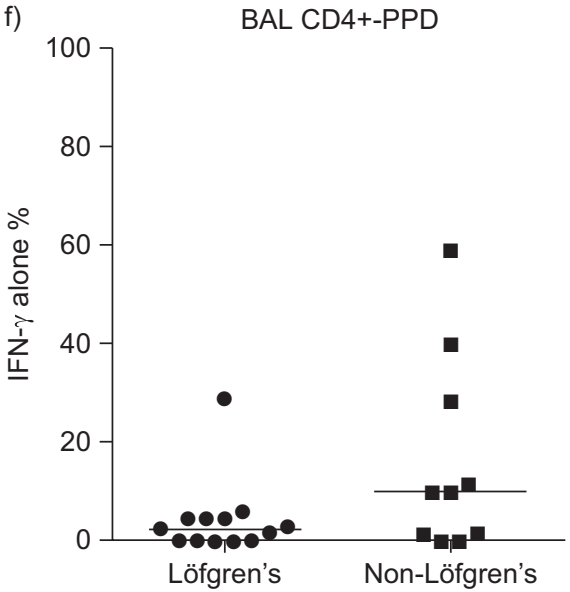

b)

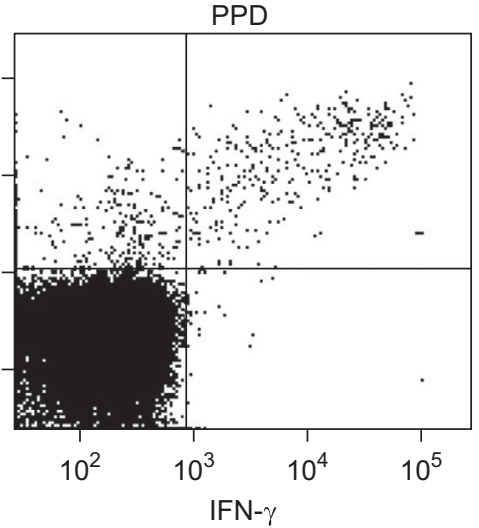

d)

BAL CD4+-mKatG

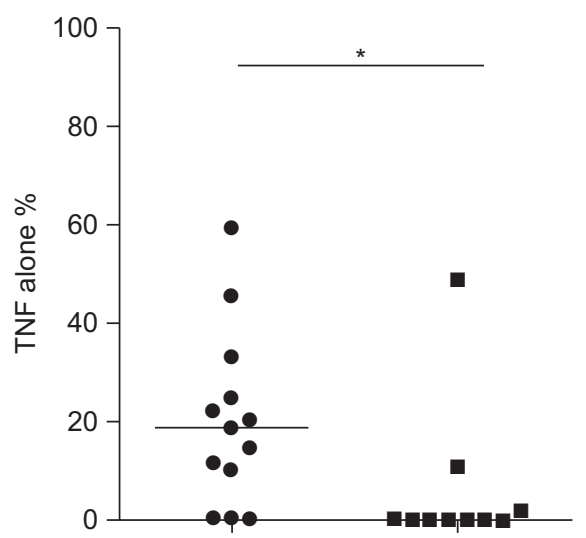

e)

BAL CD4+-mKatG

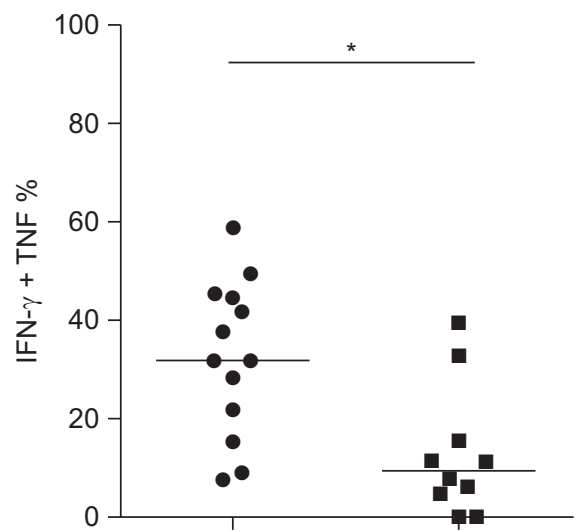

g)

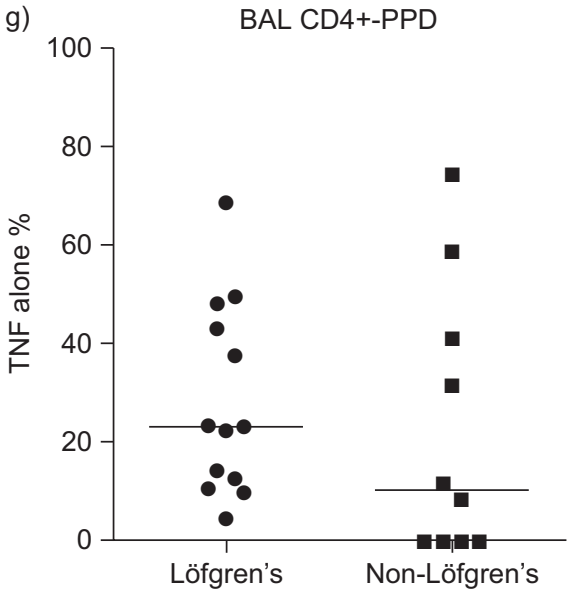

h)

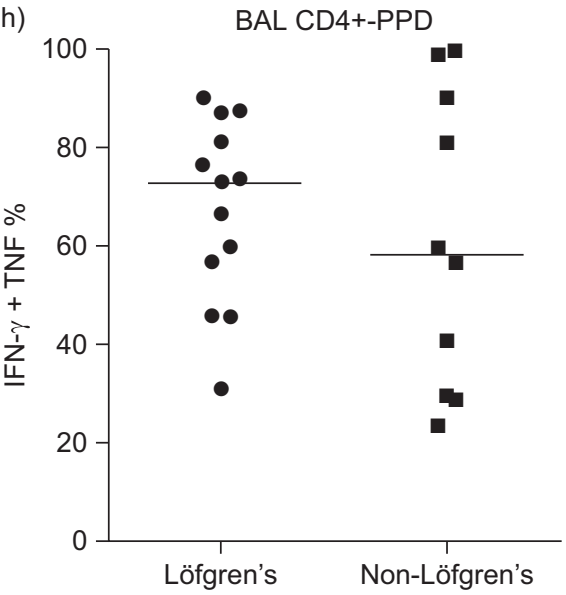

FIGURE 3. Higher proportion of multifunctional bronchoalveolar lavage (BAL) CD4+ T-cells reactive to mycobacterial catalase-peroxidase (mKatG) in Löfgren's syndrome patients compared with non-Löfgren's patients. Representative flow cytometry plots, gated on CD4+ BAL T-cells, of interferon (IFN)- $\gamma$ versus tumour necrosis factor (TNF) production in response to a) mKatG and b) purified protein derivative (PPD). Percentage of c, f) single IFN- $\gamma$, d, g) single TNF or e, h) simultaneous IFN- $\gamma$ and TNF (i.e. multifunctional) production as a fraction of the BAL CD4+ T-cells that responded to $c-e$ ) mKatG or $\mathrm{f}-\mathrm{h}$ ) PPD stimulation. The sum of all cells responding with any of these cytokine patterns was set to $100 \%$. Statistical analyses were performed after deduction of background. ——: median percentage of cytokine production. *: $p<0.05$ by MannWhitney U-test; ${ }^{* *}: \mathrm{p}<0.01$ by Mann-Whitney U-test.

We demonstrated positive IFN- $\gamma$ and TNF CD4+ T-cell responses to $\mathrm{mKatG}$ and PPD in patients with and without Löfgren's syndrome in (with a few exceptions) both BAL and blood. CD4+ T-cells have long been known as important effector cells in controlling mycobacterial infections by producing IFN- $\gamma$ [23]. The strong CD8+ response (predominantly
IFN $-\gamma$ production) to $\mathrm{mKatG}$, but not to PPD, is noteworthy. Studies in mice models have demonstrated that CD8+ T-cells are more important in antimycobacterial immune responses than previously appreciated [24-26]. One may hypothesise that CD8+ T-cells contribute to protective immunity against $M$. tuberculosis infection by a combination of cytotoxic activity and 
a)

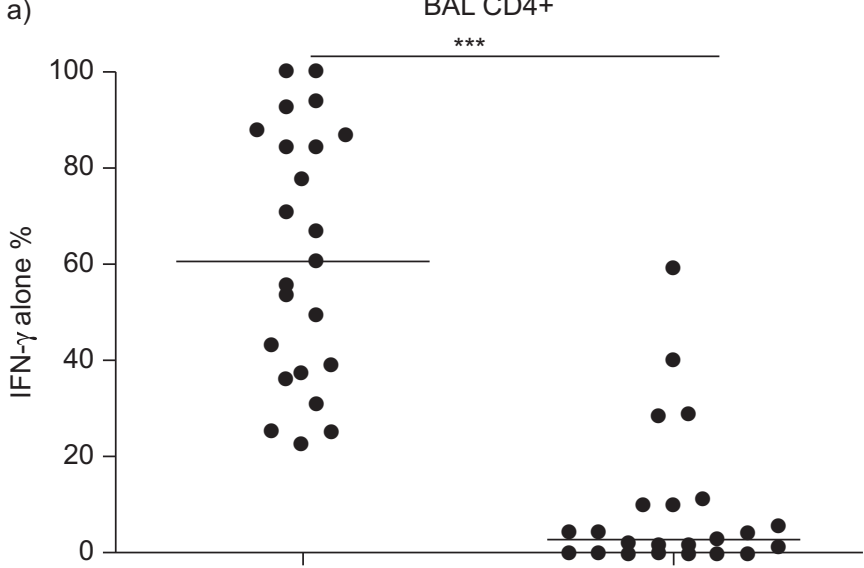

b)

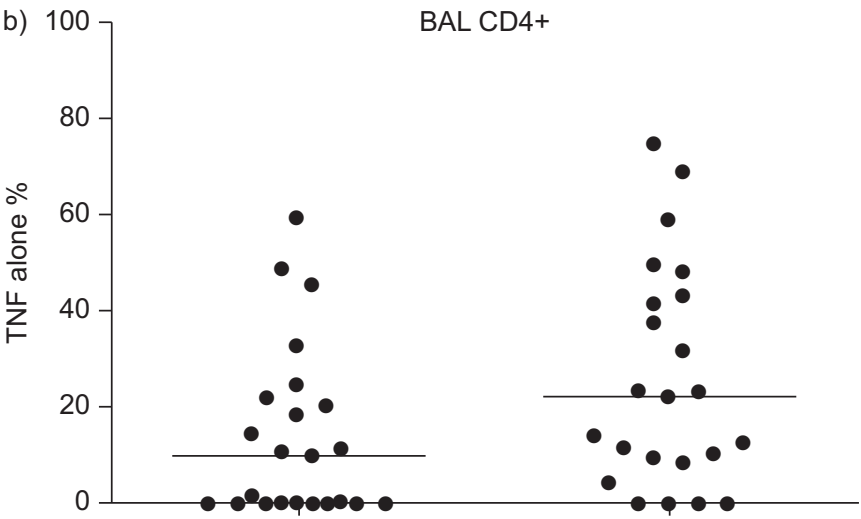

c)

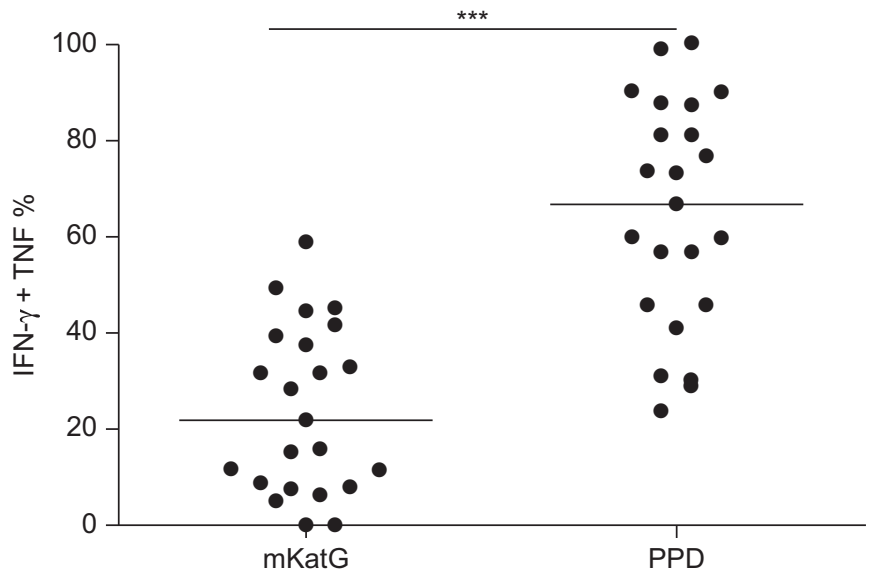

FIGURE 4. Mycobacterial catalase-peroxidase (mKatG) stimulates more single interferon (IFN)- $\gamma$ production compared with purified protein derivative (PPD) in bronchoalveolar lavage (BAL) fluid CD4+ T-cells of patients with sarcoidosis. A statistical comparison of the fractions of total mKatG- or PPD-reactive CD4+ T-cells, displaying the cytokine patterns a) IFN- $\gamma$ alone, b) tumour necrosis factor (TNF) alone or c) simultaneous IFN- $\gamma$ and TNF (i.e. multifunctional) production. The sum of all cells responding with any of these cytokine patterns was set to $100 \%$. Statistical analyses were performed after deduction of background. —_: median percentage of cytokine-expressing cells. ${ }^{* *}$ : $p<0.001$ by Wilcoxon signed-rank test.

cytokine production. In contrast to our $\mathrm{mKatG}$ results, stimulation with PPD gave rise to an IFN- $\gamma$ response only in the CD4+ T-cells in BAL and blood, but not in the CD8+ T-cell subset. This indicates a selective recognition of the mycobacterial epitopes a)

BAL CD4+-mKatG

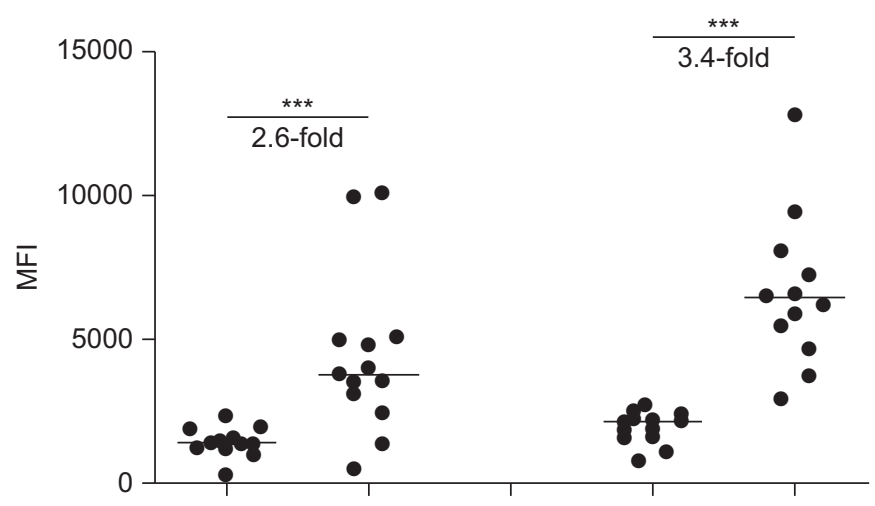

b)

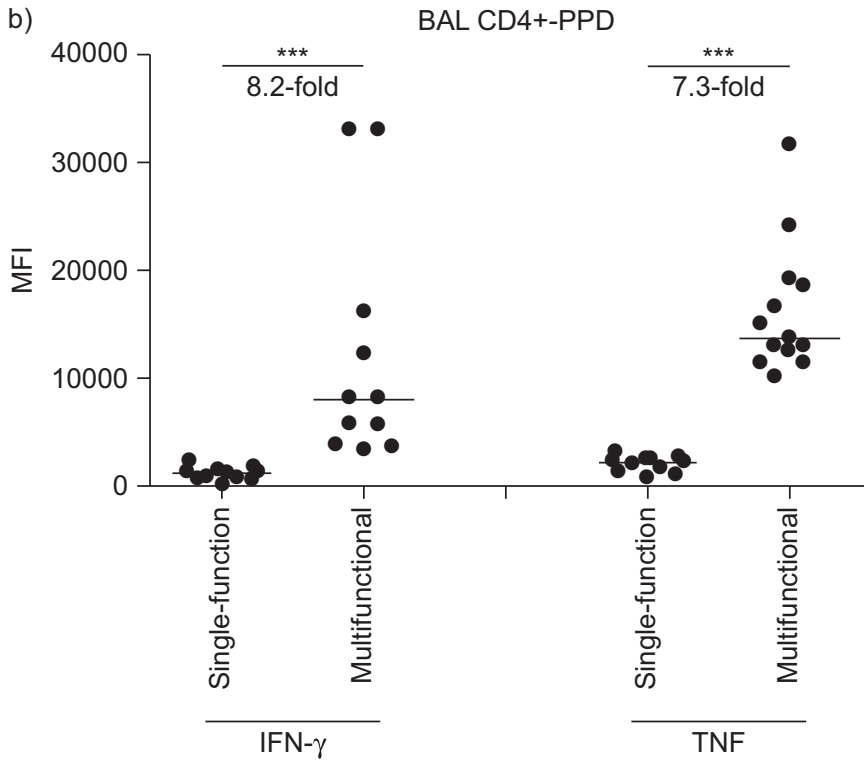

FIGURE 5. Greater median fluorescent intensity (MFI) for cytokine staining of multifunctional CD4+ T-cells of bronchoalveolar lavage (BAL). MFI for interferon (IFN) $-\gamma$ and tumour necrosis factor (TNF) of single IFN- $\gamma$, single TNF or simultaneous IFN- $\gamma$ and TNF (i.e. multifunctional) production in BAL CD4+ T-cells after stimulation with a) mycobacterial catalase-peroxidase (mKatG) or b) purified protein derivative (PPD). Only Löfgren's syndrome patients were analysed. Statistical analyses were performed after deduction of background. ——: median percentage of cytokine production. ${ }^{* * *}: p<0.001$ by Wilcoxon signed-rank test.

among T-cells. It has previously been shown that both CD4+ and CD8+ T-cells of BAL and peripheral blood respond to $\mathrm{mKatG}$ with IFN- $\gamma$ production [12]. When comparing the reactivity in BAL and blood, we found a higher cytokine response towards mKatG among BAL CD4+ T-cells, indicating that these mKatGspecific T-cells are accumulating in the affected organ. However, the CD8+ T-cells responded to $\mathrm{mKatG}$ to the same extent in BAL and blood. These findings are in agreement with those in US patients [12]. Some mKatG-derived peptides may be constituents of PPD, but it is technically challenging to identify all components of this largely degraded protein mixture, although one recent study detected peptide fragments of previously known pathogenic mycobacterial antigens [27]. Since the magnitude of BAL anti-mKatG and anti-PPD responses varied both within the Löfgren's syndrome and non-Löfgren's groups, the question arises in what proportion of 
a)

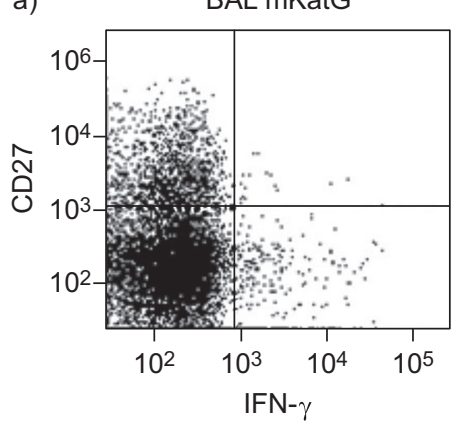

e)

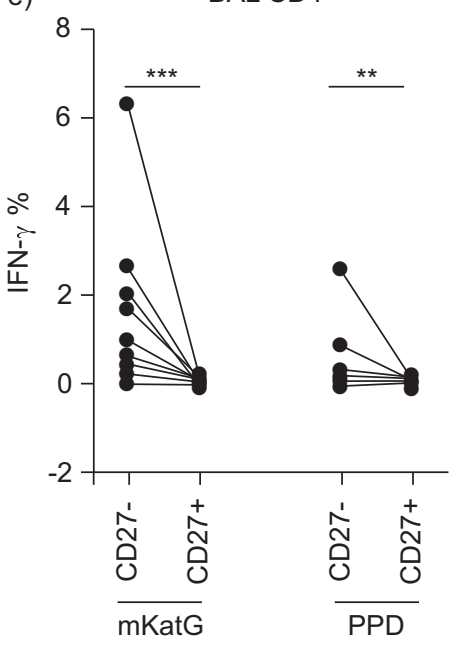

b)

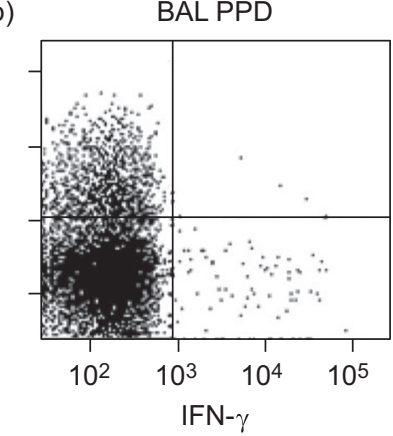

c)

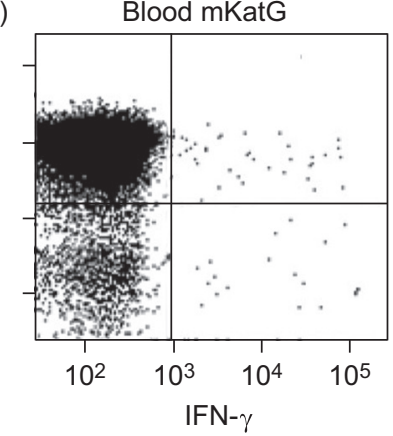

d)

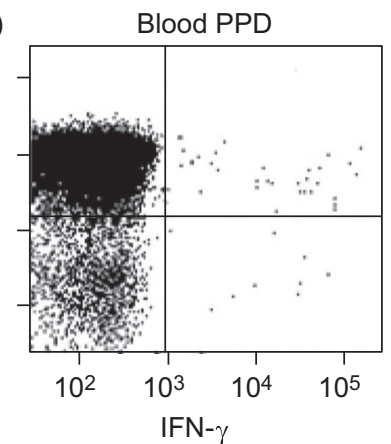

f) Blood CD4+

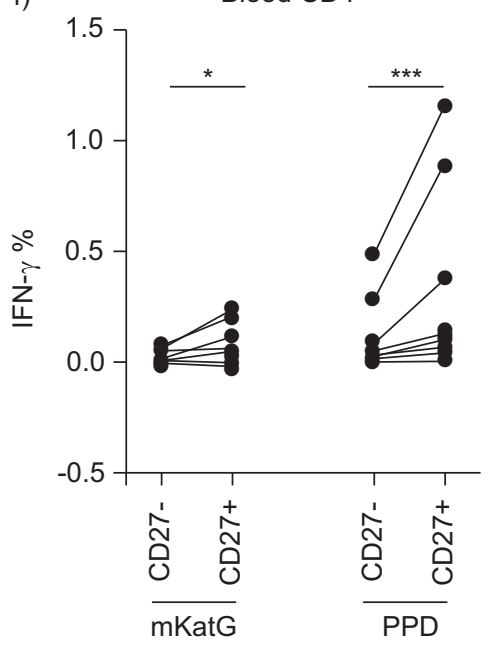

FIGURE 6. Higher bronchoalveolar lavage (BAL) CD27-, but not blood CD27+, T-cell reactivity towards mycobacterial proteins. Representative flow cytometry plots of interferon (IFN)- $\gamma$ production in a, b) BAL and c, d) whole blood CD27- or CD27+ T-cells in response to a, c) mycobacterial catalase-peroxidase (mKatG) or b, d) purified protein derivative (PPD) media alone or unstimulated whole blood were used as negative controls; superantigens Staphylococcus enterotoxin $\mathrm{A}$ and $\mathrm{B}$ were used as a positive control (data not shown). Percentages of IFN- $\gamma$-expressing CD27- or CD27+e) BAL or f) whole blood CD4+ T-cells after mKatG or PPD stimulation. Statistical analyses were performed after deduction of background. ${ }^{*}: p<0.05$ by Wilcoxon signed-rank test; **: $p<0.01$ by Wilcoxon signed-rank test; ***: $p<0.001$ by Wilcoxon signed-rank test. sarcoidosis patients these antigens are truly important. Our previous study involving both Swedish and US patients, as well as PPD+ and PPD- healthy controls, showed that $\sim 50 \%$ of patients at either location had significant T-cell responses to $\mathrm{mKatG}$ [12]. Further studies are warranted to define the clinical importance of these responses.

Although we did not include any irrelevant antigen in this study, this has previously been performed by other investigators. For example, it was shown that BAL cells from sarcoidosis patients reacted to mycobacterial antigens but not to keyhole limpet haemocyanin, demonstrating antigen specificity [13, 28]. Likewise, peripheral blood cells from a majority of sarcoidosis patients responded to stimulation with mycobacterial antigens but not lysate from Trypanosoma brucei [29]. However, it would also be of interest to compare blood and BAL responses to a common nonspecific antigen, such as tetanus or Candida spp., to see if there is a general propensity of memory T-cells to accumulate in BAL fluid, or if this is particularly the case with mycobacteria-specific cells in sarcoidosis.

Until now, we have not been able to directly demonstrate any antigen specificity among AV2S3+ T-cells accumulating in the lungs of DR3+ Scandinavian sarcoidosis patients [20]. However, we previously obtained indirect evidence from Mycobacterium bovis bacilli Calmette-Guérin-vaccinated DR3+ healthy subjects for antimycobacterial reactivity of AV2S3+ cells [15] and, in sarcoidosis patients, for reactivity against $\mathrm{mKatG}$ among these particular Th cells [12]. Our intriguing data in the present study, of $\mathrm{mKatG}$ initiating a cytokine response in the lung-accumulated AV2S3+ CD4+ T-cells, is the first to show that we have a specific disease-related antigen triggering a subset of these cells. TCR AV2S3- cells also responded to $\mathrm{mKatG}$, but not to the same extent as AV2S3+ cells, with regard to IFN- $\gamma$ production. Similar to our result in BAL, we found that the AV2S3+ T-cells in blood responded to mKatG stimulation. As in BAL, the AV2S3+ T-cells in blood produced significantly more IFN- $\gamma$ in response to $\mathrm{mKatG}$ compared with AV2S3- T-cells. How can we explain the observation that $\mathrm{mKatG}$ triggers not only different subpopulations of CD4+ T-cells, but also CD8+ T-cells? To be recognised by $\mathrm{T}$-cells, a protein must undergo so-called antigen processing, during which it is cleaved into short peptide fragments. CD4+ T-cells typically recognise peptides of 15-25 amino acids in length, presented by HLA class II molecules (such as HLADR), while CD8+ T-cells recognise even shorter peptides. Since $\mathrm{mKatG}$ is a protein of $>700$ amino acids in length, it is likely to contain several T-cell epitopes, both for different CD4+ cells as well as CD8+ cells. To definitively establish the antigenspecificity of AV2S3 cells, a confirmatory study would be needed, which should also include in vitro stimulation with individual $\mathrm{mKatG}$ peptides to identify clones of T-cells responding to the respective peptide epitopes.

The reason for the significantly higher spontaneous TNF and IL-2 production in BAL and blood AV2S3+ cells compared with AV2S3- cells is not known, but it is tempting to speculate 
that the AV2S3+ T-cells have encountered their antigen in vivo and, thus, are more activated. This would be consistent with our recent phenotypic analysis of these cells regarding expression of differentiation and activation markers [8]. If in vivo antigen triggering of AV2S3+ T-cells is the case, it may explain why they have a limited capacity to be further triggered by antigen in vitro to produce these two cytokines, in contrast with IFN- $\gamma$, which is produced to a higher extent by AV2S3+ than AV2S3- cells after mKatG stimulation.

The fact that AV2S3+ T-cells are associated with good prognosis and spontaneously resolving disease [9], in combination with our finding that they secrete effector cytokines upon $\mathrm{mKatG}$ and PPD stimulation, suggests that their function is to eliminate an offending antigen. This is also supported by other studies from our group, showing that the TCR AV2S3+ CD4+ T-cells are effector cells rather than FoxP3+ regulatory Tcells $[8,30]$. In addition, we have found that these cells are more activated and more differentiated than the AV2S3- T-cell subset $[7,8]$.

Why do not all AV2S3+ cells respond with cytokine production? It is essential to remember that the AV2S3+ cell population is not a T-cell clone. The variable $\alpha$-chain can associate with different variable $\beta$-chains [31]. MALLONE et al. [32] showed that different T-cell clones can exhibit different avidity towards the same antigen, with the outcome that some clones only proliferate, whereas others both proliferate and produce cytokines in response to a given antigen concentration. This could explain why not all AV2S3+ cells respond to in vitro $\mathrm{mKatG}$ stimulation with cytokine production.

It has become increasingly apparent that T-cell responses are functionally heterogeneous, and that the extent to which Th1 cells are multifunctional, i.e. secrete two or more of the cytokines IFN- $\gamma$, TNF and IL-2, correlates with disease outcome in several infections [33]. Multifunctional Th1 cells have in mice models been associated with enhanced protection against various pathogens, including $M$. tuberculosis [22, 34-36]. The induction of multifunctional T-cells is now a goal in clinical vaccine development $[37,38]$.

A striking difference was found between patients with and without Löfgren's syndrome when examining the singlefunction or multifunctional cytokine profile of the BAL CD4+ $\mathrm{T}$-cells reactive to $\mathrm{mKatG}$. Our data revealed that $\mathrm{mKatG}$ stimulated a smaller fraction of antigen-reactive cells to produce IFN- $\gamma$ alone, but relatively more cells to produce IFN- $\gamma$ and TNF simultaneously, or single TNF production, in patients with Löfgren's syndrome. In contrast, PPD stimulation gave rise to similar cytokine patterns in both patient subgroups. However, in the Löfgren's syndrome group, the proportion of multifunctional T-cells did not differ between AV2S3+ and AV2S3- cells but was rather a property of CD4+ cells in general in this patient subset. The fact that all Löfgren's patients were DR3+ (or expressed the structurally very similar DRB3*0101) served to increase the possibility of detecting differences between patient subgroups with distinct clinical phenotypes, since DR3+ Löfgren's syndrome patients have been shown to have a particularly good prognosis [39]. Thus, although the overall magnitude of anti-mKatG responses was similar in patients with or without Löfgren's syndrome, these findings suggest that the quality of T-cell responses against a limited number of mycobacterial antigens, such as $\mathrm{mKatG}$, may be of critical importance for disease outcome. It may be that the difference between these two forms of sarcoidosis is not due to different antigens, but due to qualitative differences (in particular degree of multifunctionality) in the cytokine response to key antigens. In addition to $\mathrm{mKatG}$, the response profile to other mycobacterial antigens is probably also of importance, as indicated by the higher PPD-induced TNF production by BAL CD4+ T-cells of patients with Löfgren's syndrome. A follow-up study of these patients will yield information as to whether the relative proportions of singlefunction and multifunctional cells have clinical implications and might be used as a biomarker to predict prognosis.

In the present study, we also compared the T-cell cytokine profiles induced by the two antigenic stimuli. The results showed how in both patient groups that mKatG, when compared with PPD, stimulated a different cytokine pattern. Stimulation with $\mathrm{mKatG}$ favoured significantly more single IFN- $\gamma$ secretion, whereas PPD stimulation resulted in significantly more of simultaneous IFN- $\gamma$ and TNF production, but very little secretion of IFN- $\gamma$ alone. Furthermore, the average per-cell cytokine content of PPD-reactive multifunctional Tcells was particularly high. In addition to chemical properties, this capacity to preferentially induce cells producing IFN- $\gamma$ alone over multifunctional cells (supposedly more efficient effector cells also in sarcoidosis) may, in part, explain the persistence of $\mathrm{mKatG}$, especially in non-Löfgren's patients. In contrast, mycobacterial antigens with PPD-like properties may be better at triggering $\mathrm{T}$-cells with a high capacity to support antigen elimination.

By studying the MFI of intracellular cytokines we found that the multifunctional CD4+ T-cells had the highest MFI values, i.e. more of each cytokine produced from each cell, when compared with single cytokine-producing CD4+ T-cells. Although this particular analysis was only performed in lung and blood cells of Löfgren's syndrome patients, the results are in line with a previous study in humans [37]. It remains to be elucidated which is of greater functional importance, i.e. that multifunctional T-cells have a larger repertoire of cytokines or that the amount of each cytokine per cell is higher. However, as suggested by animal studies, both factors are probably important [22].

T-cell differentiation is associated with loss of the costimulatory molecule CD27, and BAL T-cells were predominantly CD27-, in contrast to the situation in blood, indicating a more differentiated T-cell population in the affected organ. We found that BAL CD27- CD4+ T-cells included a higher frequency of cells producing IFN $-\gamma$ in response to $\mathrm{mKatG}$ or PPD, when compared with BAL CD27+ CD4+ T-cells; however, in blood the highest frequency of antigen-specific IFN- $\gamma$ producing cells were found in the CD27+ CD4+ T-cell subset. The findings for BAL, but not blood, are similar to what has been reported regarding beryllium-specific T-cell responses in patients with chronic beryllium disease (CBD), a granulomatous disorder that shows great similarity with sarcoidosis [40]. The differences between sarcoidosis and CBD may be related 
to the differences in antigen localisation and duration of antigen exposure.

For the first time, we show that a specific mycobacterial antigen, mKatG, stimulates a subset of the CD4+ TCR AV2S3+ T-cells, which were previously found accumulating in the lungs of DR3+ sarcoidosis patients, typically those with Löfgren's syndrome. In addition, a more pronounced multifunctional cytokine pattern of the mKatG-specific BAL CD4+ T-cells in Löfgren's syndrome patients, compared with corresponding cells in non-Löfgren's patients, might suggest that patients with Löfgren's syndrome eliminate antigen more efficiently and, thereby, obtain an improved prognosis. It is noteworthy that strong responses to $\mathrm{mKatG}$ were detected not only in CD4+, but also in CD8+, T-cells. The function of mKatG-reactive CD8+ cells should be further investigated.

A deeper understanding of specific T-cell responses associated with recovery versus chronic disease should ultimately enable the design of novel, antigen-specific therapies.

\section{SUPPORT STATEMENT}

This study was supported by the Swedish Heart-Lung Foundation, the King Oscar II Jubilee Foundation, the Swedish Research Council, the US National Institutes of Health (grant number 1 R01 HL083870), the Mats Kleberg Foundation, the Söderberg Foundation, the Stockholm County Council and Karolinska Institutet.

\section{STATEMENT OF INTEREST}

None declared.

\section{ACKNOWLEDGEMENTS}

The authors thank H. Blomqvist, M. Dahl, B. Dahlberg, B. Engvall and G. de Forest (Respiratory Medicine Unit, Dept of Medicine Solna, Karolinska Institutet, Stockholm, Sweden) for their excellent technical assistance.

\section{REFERENCES}

1 Wahlstrom J, Katchar K, Wigzell H, et al. Analysis of intracellular cytokines in CD4+ and CD8+ lung and blood T cells in sarcoidosis. Am J Respir Crit Care Med 2001; 163: 115-121.

2 Pinkston P, Bitterman PB, Crystal RG. Spontaneous release of interleukin-2 by lung $\mathrm{T}$ lymphocytes in active pulmonary sarcoidosis. N Engl J Med 1983; 308: 793-800.

3 Minshall EM, Tsicopoulos A, Yasruel Z, et al. Cytokine mRNA gene expression in active and nonactive pulmonary sarcoidosis. Eur Respir J 1997; 10: 2034-2039.

4 Muller-Quernheim J, Pfeifer S, Mannel D, et al. Lung-restricted activation of the alveolar macrophage/monocyte system in pulmonary sarcoidosis. Am Rev Respir Dis 1992; 145: 187-192.

5 Zheng L, Teschler H, Guzman J, et al. Alveolar macrophage TNF- $\alpha$ release and BAL cell phenotypes in sarcoidosis. Am J Respir Crit Care Med 1995; 152: 1061-1066.

6 Grunewald J, Janson $\mathrm{CH}$, Eklund A, et al. Restricted V 2.3 gene usage by $\mathrm{CD} 4+\mathrm{T}$ lymphocytes in bronchoalveolar lavage fluid from sarcoidosis patients correlates with HLA-DR3. Eur J Immunol 1992; 22: 129-135.

7 Katchar K, Walström J, Eklund A, et al. Highly activated T-cell receptor AV2S3+ CD4+ lung T-cell expansions in pulmonary sarcoidosis. J Am J Respir Crit Care Med 2001; 163: 1540-1545.

8 Wiken M, Grunewald J, Eklund A, et al. Multiparameter phenotyping of T-cell subsets in distinct subgroups of patients with pulmonary sarcoidosis. J Intern Med 2012; 271: 90-103.
9 Planck A, Eklund A, Grunewald J. Markers of activity in clinically recovered human leukocyte antigen-DR17-positive sarcoidosis patients. Eur Respir J 2003; 21: 52-57.

10 Saboor SA, Johnson NM, McFadden J. Detection of mycobacterial DNA in sarcoidosis and tuberculosis with polymerase chain reaction. Lancet 1992; 339: 1012-1015.

11 Song Z, Marzilli L, Greenlee BM, et al. Mycobacterial catalaseperoxidase is a tissue antigen and target of the adaptive immune response in systemic sarcoidosis. J Exp Med 2005; 201: 755-767.

12 Chen ES, Wahlstrom J, Song $\mathrm{Z}$, et al. $\mathrm{T}$ cell responses to mycobacterial catalase-peroxidase profile a pathogenic antigen in systemic sarcoidosis. J Immunol 2008; 181: 8784-8796.

13 Oswald-Richter KA, Culver DA, Hawkins C, et al. Cellular responses to mycobacterial antigens are present in bronchoalveolar lavage fluid used in the diagnosis of sarcoidosis. Infect Immun 2009; 77: 3740-3748.

14 Drake WP, Dhason MS, Nadaf M, et al. Cellular recognition of Mycobacterium tuberculosis ESAT-6 and KatG peptides in systemic sarcoidosis. Infect Immun 2007; 75: 527-530.

15 Esin S, Batoni G, Saruhan-Direskeneli G, et al. In vitro expansion of T-cell-receptor $\mathrm{V} \alpha 2.3^{+} \mathrm{CD}^{+} \mathrm{T}$ lymphocytes in HLA-DR17(3), $\mathrm{DQ}^{+}$individuals upon stimulation with Mycobacterium tuberculosis. Infect Immun 1999; 67: 3800-3809.

16 Statement on sarcoidosis. Joint Statement of the American Thoracic Society (ATS), the European Respiratory Society (ERS) and the World Association of Sarcoidosis and Other Granulomatous Disorders (WASOG) adopted by the ATS Board of Directors and by the ERS Executive Committee, February 1999. Am J Respir Crit Care Med 1999; 160: 736-755.

17 Grunewald J, Eklund A. Sex-specific manifestations of Lofgren's syndrome. Am J Respir Crit Care Med 2007; 175: 40-44.

18 Grunewald J, Wigzell H. T-cell expansions in healthy individuals. Immunologist 1996; 4: 99-103.

19 Grunewald J, Wahlstrom J, Berlin M, et al. Lung restricted T cell receptor AV2S3+CD4+ T cell expansions in sarcoidosis patients with a shared HLA-DR $\beta$ chain conformation. Thorax 2002; 57: 348-352.

20 Grunewald J, Olerup O, Persson U, et al. T-cell receptor variable region gene usage by $\mathrm{CD} 4+$ and $\mathrm{CD} 8+\mathrm{T}$ cells in bronchoalveolar lavage and peripheral blood of sarcoidosis patients. Proc Natl Acad Sci USA 1994; 91: 4965-4969.

21 Eklund A, Blaschke E. Relationship between changed alveolarcapillary permeability and angiotensin converting enzyme activity in serum in sarcoidosis. Thorax 1986; 41: 629-634.

22 Darrah PA, Patel DT, De Luca PM, et al. Multifunctional TH1 cells define a correlate of vaccine-mediated protection against Leishmania major. Nat Med 2007; 13: 843-850.

23 Chackerian AA, Perera TV, Behar SM. Gamma interferonproducing $\mathrm{CD} 4+\mathrm{T}$ lymphocytes in the lung correlate with resistance to infection with Mycobacterium tuberculosis. Infect Immun 2001; 69: 2666-2674.

24 Mittrucker HW, Steinhoff U, Kohler A, et al. Poor correlation between $\mathrm{BCG}$ vaccination-induced $\mathrm{T}$ cell responses and protection against tuberculosis. Proc Natl Acad Sci USA 2007; 104: 12434-12439.

25 van Pinxteren LA, Cassidy JP, Smedegaard BH, et al. Control of latent Mycobacterium tuberculosis infection is dependent on CD8 T cells. Eur J Immunol 2000; 30: 3689-3698.

26 Serbina NV, Flynn JL. Early emergence of $\mathrm{CD}^{+} \mathrm{T}$ cells primed for production of type 1 cytokines in the lungs of Mycobacterium tuberculosis-infected mice. Infect Immun 1999; 67: 3980-3988.

27 Borsuk S, Newcombe J, Mendum TA, et al. Identification of proteins from tuberculin purified protein derivative (PPD) by LCMS/MS. Tuberculosis (Edinb) 2009; 89: 423-430.

28 Oswald-Richter KA, Beachboard DC, Zhan X, et al. Multiple mycobacterial antigens are targets of the adaptive immune response in pulmonary sarcoidosis. Respir Res 2010; 11: 161. 
29 Carlisle J, Evans W, Hajizadeh R, et al. Multiple Mycobacterium antigens induce interferon-gamma production from sarcoidosis peripheral blood mononuclear cells. Clin Exp Immunol 2007; 150: 460-468.

30 Idali F, Wahlstrom J, Muller-Suur C, et al. Analysis of regulatory T cell associated forkhead box $\mathrm{P} 3$ expression in the lungs of patients with sarcoidosis. Clin Exp Immunol 2008; 152: 127-137.

31 Grunewald J, Hultman T, Bucht A, et al. Restricted usage of T cell receptor $\mathrm{V} \alpha / \mathrm{J} \alpha$ gene segments with different nucleotide but identical amino acid sequences in HLA-DR3+ sarcoidosis patients. Mol Med 1995; 1: 287-296.

32 Mallone R, Kochik SA, Laughlin EM, et al. Differential recognition and activation thresholds in human autoreactive GAD-specific Tcells. Diabetes 2004; 53: 971-977.

33 Seder RA, Darrah PA, Roederer M. T-cell quality in memory and protection: implications for vaccine design. Nat Rev Immunol 2008; 8: 247-258.

34 Bogdan C, Moll H, Solbach W, et al. Tumour necrosis factor- $\alpha$ in combination with interferon- $\gamma$, but not with interleukin 4 activates murine macrophages for elimination of Leishmania major amastigotes. Eur J Immunol 1990; 20: 1131-1135.

35 Lindenstrom T, Agger EM, Korsholm KS, et al. Tuberculosis subunit vaccination provides long-term protective immunity characterized by multifunctional CD4 memory T cells. J Immunol 2009; 182: 8047-8055.

36 Forbes EK, Sander C, Ronan EO, et al. Multifunctional, high-level cytokine-producing Th1 cells in the lung, but not spleen, correlate with protection against Mycobacterium tuberculosis aerosol challenge in mice. J Immunol 2008; 181: 4955-4964.

37 Huaman MC, Mullen GE, Long CA, et al. Plasmodium falciparum apical membrane antigen 1 vaccine elicits multifunctional CD4 cytokine-producing and memory T cells. Vaccine 2009; 27: 5239-5246.

38 Goonetilleke N, Moore S, Dally L, et al. Induction of multifunctional human immunodeficiency virus type 1 (HIV-1)-specific $\mathrm{T}$ cells capable of proliferation in healthy subjects by using a prime-boost regimen of DNA- and modified vaccinia virus Ankara-vectored vaccines expressing HIV-1 Gag coupled to CD8+ T-cell epitopes. J Virol 2006; 80: 4717-4728.

39 Grunewald J, Eklund A. Lofgren's syndrome: human leukocyte antigen strongly influences the disease course. Am J Respir Crit Care Med 2009; 179: 307-312.

40 Mack DG, Lanham AM, Palmer BE, et al. CD27 expression on CD4+ T cells differentiates effector from regulatory $\mathrm{T}$ cell subsets in the lung. J Immunol 2009; 182: 7317-7324. 